\title{
Age-related differences in diabetes care outcomes in Korea: a retrospective cohort study
}

\author{
Myung Ki ${ }^{1}$, Sujin Baek ${ }^{2}$, Young-duk Yun², Namhoon Kim³ ${ }^{3}$ Martin Hyde ${ }^{4}$ and Baegju Na ${ }^{5^{*}}$
}

\begin{abstract}
Background: Age-related differences in diabetes outcomes are important both for clinical and policy considerations. To clarify the basis of such differences, we investigated patterns of associations for age in relation to hospitalization and glycemic control and examined the role of other factors.

Methods: 4471 patients with diabetes aged 40-79 years were drawn from a retrospectively retrieved National Health Insurance Cohort. Using logistic regression, risk factors measured over the two years (2007-2008) were examined for their associations with hospitalization and poor glycemic control during the last year (2009) of follow-up.

Results: Compared to the middle-aged patients, older patients were more likely to have been hospitalized (Adjusted odds ratio $\left(O R_{\text {adjusted }}\right)=1.97(95 \% \mathrm{Cl}=1.28$, 3.04) for the oldest group (ages 70-79) vs youngest group (ages 40-49)) but less likely to have poor glycemic control $\left(\mathrm{OR}_{\text {adjusted }}=0.45(95 \% \mathrm{Cl}=0.37,0.56)\right.$ for the oldest group vs youngest group). Older patients were also less likely to be obese but had more complications, longer duration of diabetes, lower continuity of care, and higher blood pressure and total cholesterol level. The pattern of associations for hospitalization and glycemic control was not uniform across the risk factors, sharing only a few common factors such as the duration of diabetes and blood pressure. In general, poor glycemic control was affected predominantly by metabolic management, while hospitalization was strongly related to functional status (i.e., number of complications) and care quality measures (i.e., continuity of care).
\end{abstract}

Conclusion: Hospitalization was higher among the older diabetic patients, despite better glycemic control. Factors were differently associated with the two diabetes-related outcomes, providing more comprehensive risk profiles for hospitalization. The co-existence of improved glycemic control and increased hospitalization among older diabetic patients suggests an extension of a geriatric evaluation to wider functional and comorbidity status.

Keywords: Type 2 diabetes, Diabetes management among older patients, Hospitalization, Glycemic control, Risk factors

\section{Background}

The recent epidemic of type 2 diabetes is a global concern $[1,2]$. The rise in the prevalence of diabetes has become increasingly alarming, as it has coincided with population aging. South Korea (hereafter Korea) has one of the fastest aging population in the world and this has been accompanied by a surge of diabetes among the older population. According to a representative Korean national survey [3], the standardized prevalence of diabetes among adults aged over 30 increased from $8.9 \%$ to $10.1 \%$ between 2001 and

\footnotetext{
* Correspondence: skqw@konyang.ac.kr

${ }^{5}$ Department of Preventive Medicine, College of Medicine, Konyang University, Konyang Univ. Gwanjeo Campus, Gasuwon-dong, Seo-gu, Daejeon 302-833, Korea

Full list of author information is available at the end of the article
}

2010, while the corresponding figure for those aged 65 or older was $16.6 \%$ to $22.7 \%$.

This is a major concern as older diabetic patients are known to have more complications [4], and a higher rate of hospitalization [5-7], and mortality [8]. However, the majority of studies, both those using community and patients based samples [9-13] including Korean studies $[3,14]$, consistently have shown a clear inverse relationship between age and glycemic control among diabetic patients, though some studies $[15,16]$ only observed better glycemic control among the oldest-old age group. Overall, this suggests that better glycemic control and other adverse consequences co-exist amongst older diabetic patients. To date, research has focused on such outcomes separately; 
only a few previous studies $[9,11,17]$ have pointed out the inverse association between age and glycemic control versus other important diabetes-related outcomes and none of them has actually examined the associations.

Furthermore, there is some evidence that the relationship between age and better glycemic control may be simply attributed to other characteristics such as BMI (body mass index) [18] and duration of diabetes [19]. Older patients with diabetes tended to be leaner than younger patients, and so this may explain their better glycemic control. Similarly, some studies have shown that age affects glycemic control mainly through the interaction with duration of disease [20], others have only found this effect for those aged 80 and over [19], while other studies found persistent effects of age even after consideration of duration of diabetes $[11,13,21]$. Thus, to clarify these age-related associations, we investigated whether age predicts a greater likelihood of hospitalization and better glycemic control in older patients with type 2 diabetes and, if so, whether the association is independent of other covariates.

Diabetes is a major source of potentially avoidable hospitalization. It is broadly described as an ambulatory care-sensitive condition, for which the provision of quality out-patient care may play a critical role [22]. However, the direct cost of diabetes attached to inpatient care is considerable and on the rise [23] and thus the identification of factors linked to an increased risk of hospitalization may enable considerable financial savings. This is particularly important in the Korean context, where the gap in diabetes management is highlighted by the very high rates of hospitalization relative to the moderate prevalence of diabetes [24]. Consequently, there has been a growing demand for research to examine the risk factors for increased hospitalization [6,25]. To assess the prevalence of hospitalization, we investigated measures for quality of diabetes care such as continuity of care, defined as the provision of diabetes care by a usual provider for a period [26], in relation to two patient outcomes (i.e., hospitalization and glycemic control).

Based on a large nationally representative sample linked to clinical data, we aimed to address whether 1) the patterns of age-related associations differ between hospitalization and glycemic control, 2) the age-related associations are independent of other common characteristics of patients with diabetes, and 3) a set of risk factors from various areas are differently associated with hospitalization and glycemic control in direction and magnitude.

\section{Methods}

\section{Study population}

For the current study, 4471 patients diagnosed with diabetes were selected from the Korean National Health Insurance claims data. Korean National Health Insurance is a compulsory enrolment scheme and covers the whole population. Data for 989,887 people from the Korean National Health Insurance were retrospectively collected from January 2001 to December 2009 (Korean National Health Insurance Cohort). The full details of the data construction procedures are described elsewhere [27]. Briefly, the data were drawn based on eight stratification variables (i.e., gender, age, occupation, residential area, types of health insurance, level of premium, mortality and regular health check-up) to proportionately represent $2 \%$ of the Korean population and included a variety of information on medical records and laboratory tests.

Several inclusion criteria were applied to deliver the sample used in the current study. Firstly, type 2 diabetic patients aged between 40 and 79 in 2007 were identified from the cohort $(n=60397)$, via a primary or a secondary diagnosis from insurance claims data, according to the Korean coding system based on ICD 10. Those aged 80 and over were excluded, due to the survival effects often observed for the extremely old age group [16]. Secondly, of those, patients who had been diagnosed at 2001 or who were newly diagnosed between 2002 and 2006 were retained as a baseline sample and followed-up from 2007 to 2009. We excluded those who were newly diagnosed with diabetes after 2007 due to the large variation seen in early years of the disease. Thirdly, patients who made outpatient visits for diabetes less than four times between 2007 and 2008 were also excluded to provide robust measures for some estimates and to assure diagnosis validity. Fourthly, data were further restricted to allow linkage with health examination records including laboratory tests, which were taken as part of the regular national health examination depending on varying eligible criteria (i.e., age and gender). This left 4471 type 2 diabetic patients who met these criteria. Ethical approval was obtained from Institutional Research Board at Konyang University and this study conducted through a secondary data analysis without a personal identifier.

\section{Measures}

The two outcome variables, hospitalization and glycemic control indicated by fasting plasma glucose (FPG), were collected in 2009, the last year of the 9 year follow-up period. Hospitalization was defined as occurring when a patient was admitted for more than one day for a primary or a secondary diagnosis of diabetes, cardiovascular disease, cerebrovascular disease, or renal disease. For glycemic control, a value of FPG greater than $126 \mathrm{mg} / \mathrm{dL}$ was taken to indicate hyperglycemia in accordance with the American Diabetic Association (ADA)'s recommendation [28]. If there were more than two FPG values within 2009, the last measurement was used.

A range of predictors were mostly measured over 2007-2008, unless otherwise specified. Age at 2007 was categorized into four groups (ages 40-49, 50-59, 60-69 
and 70-79). These groups were aggregated into two groups (ages 40-59 and 60-79) for some analyses. Predictors from the health examination records (i.e., FPG, blood pressure, total cholesterol and BMI) were drawn from 2007 or 2008. When data from more than one laboratory were available, the data collected closest to the 31st December 2007 were selected. Binary variables for hypertension and hypercholesterolemia were defined according to recent ADA and National Cholesterol Education Program Expert Panel recommendation [28,29] respectively: whether they reached levels of systolic blood pressure $(\mathrm{SBP}) \geq 140 \mathrm{mmHg}$ or diastolic blood pressure $(\mathrm{DBP}) \geq 90 \mathrm{mmHg}$ and total serum cholesterol $\geq 240 \mathrm{mg} /$ dL. BMI $\left(\mathrm{kg} / \mathrm{m}^{2}\right)$ was calculated using height and weight and categorized into three groups; normal $(<25)$, overweight (25-29.9), and obese $(\geq 30)$. Prior hospitalization between 2007 and 2008 and prior glycemic control were defined for the same categories as defined above. FPG values from two different years were at least six months apart to represent glycemic control over a different period. Other clinical characteristics at 2008 included duration of diabetes (three categories; 3-5, 6-8 and $\geq 9$ yrs) and number of complications (three categories; $0,1-2$ and $\geq 3$ ). Diabetic complications were counted, depending on the presence of six categories of micro-vascular (i.e., nephropathy, retinopathy, and neuropathy) and macro-vascular complications (i.e., peripheral vascular disease, cerebrovascular disease, and cardiovascular disease). Health service utilization measures included types of main medical institution attended (five categories; public health centre, clinic, hospital, general hospital and tertiary hospital) and continuity of care measured with continuity of care index (COCI) to assess levels of continuity of the physicianpatient relationship $[25,30]$.The equation for $\mathrm{COCI}$ is:

$$
\text { Continuity of Care Index }=\frac{\sum_{j=1}^{M} n_{j}^{2}-N}{N(N-1)}
$$

where $\mathrm{N}=$ total number of visits, $\mathrm{n}_{\mathrm{j}}=$ number of visits to provider $\mathrm{j}$, and $\mathrm{M}=$ total number of providers. COCI measured over two years (2007-2008) ranged between 0 and 1 (the higher the value the higher the continuity) and was dichotomized into two groups; having been seen always by the same physician $(\mathrm{COCI}=1)$ vs not always $(\mathrm{COCI}<1)$. The cost of the Korean national health insurance premium was calculated based on an individual's financial status, which was transformed into quartile as a marker for socioeconomic status.

\section{Statistical analysis}

We first conducted simple bivariate analyses to assess the associations of age and covariates with hospitalization and glycemic control using Chi-square tests. Then, multivariate associations were assessed using logistic regression. We undertook two models fitted with different adjustments for covariates to evaluate the pattern of associations of various risk factors with hospitalization and glycemic control. Firstly, Model 1 was fitted for each predictor with only a basic adjustment for gender and age. Secondly, additional adjustments were made for all other variables; prior hospitalization, prior glycemic control, hypertension, hypercholesterolemia, BMI, duration of diabetes, number of complications, types of main medical institution attended, continuity of care, and level of insurance premium (Model 2). To assess the independent association of age with hospitalization and glycemic control, the analyses were repeated on the basic model (i.e., gender and age only model) with separate adjustments for each predictor and which was then compared to the magnitude of the association in the basic model. As a further check, we tested interactions between age and each predictor to see whether the associations between age and hospitalization and glycemic control depended on the level of other variables. For a graphical illustration of the relationship, adjusted prevalence was presented. Adjusted prevalence was calculated by applying the parameter estimates to the mean values of variables, based on the logistic regression model with age and each predictor (as one combined variable, $x_{1}$ ) and gender $\left(x_{2}\right)$. gth stratum of $x_{1}$ (probability $P_{g}\left(x_{1}\right)$ ) can be written;

$$
p_{g}\left(x_{1}\right)=\frac{\exp ^{\left(\alpha+\beta_{g} x_{1}+\beta_{2} x_{2}\right)}}{1+\exp ^{\left(\alpha+\beta_{g} x_{1}+\beta_{2} x_{2}\right)}}
$$

Apart from the calculation of adjusted prevalence which was done manually, analyses were performed using SAS 9.1 for Windows.

\section{Results}

Among a total of 4471 patients with diabetes followed for 9 years, about half $(48.8 \%)$ of participants were aged $\geq 60$ and $46 \%$ were female (Table 1). Compared to the middle-aged group, the older group had relatively better glucose management both in 2007 and 2009 and a lower BMI in 2007. However, the group had greater rates of hospitalization in both years and higher BP and total cholesterol levels. A more frequent diabetes-related hospitalization and complications, longer duration of diabetes and lower continuity of care were seen among the older patients.

The bivariate relationships between predictors and both outcomes are shown in Table 2. Female patients were less likely to have poor glycemic control. Age was the only factor that showed opposing and statistically significant patterns of association with hospitalization (9.6\% for the youngest group vs $16.8 \%$ for the oldest 
Table 1 Sample characteristics ${ }^{*}$ of middle-aged $(n=2291$, $51.2 \%$ ) and older $(n=2180,48.8 \%$ ) patients with diabetes

\begin{tabular}{llll}
\hline $\begin{array}{l}\text { Middle-aged } \\
(\mathbf{4 0 - 5 9 )}\end{array}$ & $\begin{array}{l}\text { Older } \\
(\mathbf{6 0 - 7 9 )}\end{array}$ & Total \\
\hline$N(\%)$ & $N(\%)$ & $p$-value & $N(\%)$
\end{tabular}

\section{Gender}

Male

Female

$1515(66.1)$

$1176(54.0)$

776(33.9)

1004(46.0)

$<0.001$

2691(60.2)

Hospitalization

No

Yes

2055(89.7)

1844(84.6)

236(10.3)

336(15.4)

$<0.001$

3899(87.2)

572(12.8)

Reasons for

hospitalization

Diabetes
Cardiovascular
disease
Cerebrovascular
disease
Renal disease
Glycemic control
Controlled
Uncontrolled
( $\geq 126$ mg/dL)
Prior hospitalization

\section{No}

Hospitalized

Prior glycemic

control

\section{Controlled}

Uncontrolled

( $\geq 126 \mathrm{mg} / \mathrm{dL}$ )

Hypertension

Normal
Hypertensive $^{\dagger}$

$98(4.2)$
$76(3.3)$
$46(2.0)$
$16(0.7)$

$153(7.0)$
$96(4.4)$

925(40.4)

1132(51.9)

1366(59.6)

1048(48.1)

60(2.8)

27(1.2)

$<0.001$

251(5.6)

172(3.8)

106(2.4)

43(1.0)

2057(46.0)

2414(54.0)

\section{9(83.3)}

1660(76.1)

382(16.7)

520(23.9)

$<0.001$

3569(79.8)

902(20.2)

\section{Total cholesterol}

level

\section{Desirable \\ High( $\geq 240$ \\ $\mathrm{mg} / \mathrm{dL}$ )}

BMI, $\mathrm{kg} / \mathrm{m}^{2}$

Normal $(<25)$

Overweight

(25-29.9)

Obese $(\geq 30$ )

995(43.4)

1121(51.4)

1296(56.6)

1059(48.6)

2116(47.3)

2355(52.7)

1738(75.9)

1476(67.7)

3214(71.9)

553(24.2)

704(32.3)

$<0.001$

1257(28.1)

3985(89.1)

486(10.9)

241(10.6)

245(11.3)

0.44

.

2487(55.6)

1743(40.0)

$241(5.4)$

Duration of diabetes

$$
\begin{aligned}
& 3-5 \text { yrs } \\
& 6-8 \text { yrs }
\end{aligned}
$$$$
\text { 861(37.6) }
$$$$
\text { 608(26.6) }
$$

822(35.9)$$
\text { 607(27.9) }
$$$$
\text { 529(24.3) }
$$

1230(56.4)

846(38.8)

104(4.8)

0.17

$1044(47.9)<0.001$
Table 1 Sample characteristics ${ }^{*}$ of middle-aged ( $n=2291$, $51.2 \%)$ and older $(n=2180,48.8 \%)$ patients with diabetes (Continued)

Number of

complications

$\begin{array}{cllll}\text { No } & 850(37.1) & 607(27.8) & & 1457(32.6) \\ 1-2 & 1200(52.4) & 1212(55.6) & & 2412(54.0) \\ \geq 3 & 241(10.5) & 361(16.5) & <0.001 & 602(13.5) \\ \text { Continuity of care } & & & & \\ \text { High } & & & & 2343(52.4) \\ \text { Low } & 1345(58.7) & 998(45.8) & & 2128(47.6)\end{array}$

Types of main medical institution

\begin{tabular}{|c|c|c|c|c|}
\hline Tertiary hospital & $182(7.9)$ & $158(7.2)$ & & $340(7.6)$ \\
\hline General hospital & $358(15.6)$ & $250(11.5)$ & & 608(13.6) \\
\hline Hospital & 128(5.6) & $92(4.2)$ & & $220(4.9)$ \\
\hline Clinic & 1534(67.0) & 1458(66.9) & & 2992(66.9) \\
\hline $\begin{array}{l}\text { Public health } \\
\text { centre }\end{array}$ & $89(3.9)$ & $222(10.2)$ & $<0.01$ & $311(7.0)$ \\
\hline
\end{tabular}
attended

Level of health

insurance premium

$\begin{array}{lllll}\text { Lowest quartile } & 447(19.5) & 484(22.2) & & 931(20.8) \\ \text { Second quartile } & 420(18.3) & 399(18.3) & & 819(18.3) \\ \text { Third quartile } & 649(28.3) & 556(25.5) & & 1205(27.0) \\ \begin{array}{l}\text { Highest } \\ \text { quartile }\end{array} & 775(33.8) & 741(34.0) & 0.07 & 1516(33.9) \\ & & & & \end{array}$

*Hospitalization and glycemic control were measured at 2009, while other measures including prior hospitalization and prior glycemic control were measured between 2007 and 2008.

${ }^{\dagger} \mathrm{SBP} \geq 140 \mathrm{mmHg}$ or $\mathrm{DBP} \geq 90 \mathrm{mmHg}$.

${ }^{\ddagger} \mathrm{High}$, if Continuity of Care Index $=1$ and low otherwise.

${ }^{\S} \mathrm{p}$-value was obtained from Chi-square test.

group, $\mathrm{p}<0.001)$ and poor glycemic control $(63.7 \%$ for the youngest group vs $43.7 \%$ for the oldest group, $\mathrm{p}<0.001$ ). The pattern of association between age and both hospitalization and controlled glucose was gradual across age groups. Prior hospitalization and prior poor glycemic control strongly affected the recurrence of each outcome but with no cross-associations. For example, $23.1 \%$ of those with a prior history of hospitalization had been readmitted in two years later, while this was true for only $10.2 \%$ of those without a prior history. Hypertension and high total cholesterol level were unfavourably associated with better glycemic control. Compared to those with a short duration of diabetes, those with a long duration of diabetes had both higher rates of hospitalization and more frequent poor glycemic control. A greater number of complications and poor continuity of care predicted frequent hospitalization but not glycemic control. No statistical associations were seen for BMI, types of main medical institution attended, and the amount of health insurance premium. 
Table 2 Prevalence of hospitalization and poor glycemic control (2009) among diabetic patients by socio-demographic and clinical factors (2007-2008)

\begin{tabular}{|c|c|c|c|c|}
\hline & $\begin{array}{c}\text { Hospitalization } \\
\text { (\%) }\end{array}$ & p-value f $^{\ddagger}$ & $\begin{array}{c}\text { Poor } \\
\text { glycemic } \\
\text { control }(\%)\end{array}$ & p-value ${ }^{\ddagger}$ \\
\hline
\end{tabular}

Gender

Male

Female

Age groups

40-49

50-59

60-69

70-79

Prior

hospitalization

No

Hospitalized

Prior glycemic

control

\section{Controlled \\ Uncontrolled}

( $\geq 126 \mathrm{mg} / \mathrm{dL}$ )

Hypertension*

\section{Normal}

Hypertensive

Total cholesterol level

Desirable

$\operatorname{High}(\geq 240$

$\mathrm{mg} / \mathrm{dL}$ )

BMI, kg/m²

Normal $(<25)$

Overweight

(25-29.9)

Obese $(\geq 30)$

Duration of

diabetes

$$
\begin{aligned}
& \text { 3-5 yrs } \\
& 6-8 \text { yrs } \\
& \geq 9 \text { yrs }
\end{aligned}
$$

Number of complications

$$
\begin{aligned}
& \text { No } \\
& 1-2 \\
& \geq 3
\end{aligned}
$$

Continuity of care ${ }^{t}$

$$
\begin{aligned}
& \text { High } \\
& \text { Low }
\end{aligned}
$$

\section{2}

13.8

0.11

\section{7}

51.5

0.006

63.7

58.0

51.2

43.7

$<0.001$

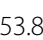

56.2

0.42

37.9

68.4

13.7

0.07

11.2

14.5

0.0025

53.1

56.3

0.03

53.4

58.4

\begin{tabular}{|c|c|c|c|c|}
\hline \multicolumn{5}{|l|}{$\begin{array}{l}\text { Types of main } \\
\text { medical institution } \\
\text { attended }\end{array}$} \\
\hline Tertiary hospital & 14.1 & & 46.6 & \\
\hline $\begin{array}{l}\text { General } \\
\text { hospital }\end{array}$ & 13.8 & & 52.6 & \\
\hline Hospital & 18.2 & & 55.3 & \\
\hline Clinic & 12.2 & & 55.1 & \\
\hline $\begin{array}{l}\text { Public health } \\
\text { centre }\end{array}$ & 11.6 & 0.07 & 53.4 & 0.07 \\
\hline \multicolumn{5}{|l|}{$\begin{array}{l}\text { Level of health } \\
\text { insurance } \\
\text { premium }\end{array}$} \\
\hline Lowest quartile & 13.0 & & 54.0 & \\
\hline Second quartile & 12.3 & & 55.3 & \\
\hline Third quartile & 14.0 & & 53.5 & \\
\hline Highest quartile & 11.9 & 0.39 & 53.7 & 0.87 \\
\hline
\end{tabular}

Table 2 Prevalence of hospitalization and poor glycemic control (2009) among diabetic patients by socio-demographic and clinical factors (2007-2008) (Continued)

${ }^{*} \mathrm{SBP} \geq 140 \mathrm{mmHg}$ or DBP $\geq 90 \mathrm{mmHg}$.

${ }^{\dagger}$ High, if Continuity of Care Index $=1$ and low otherwise.

${ }^{\ddagger} \mathrm{p}$-value was obtained from Chi-square test.

In the logistic regression analyses (Table 3), older age was associated negatively with hospitalization and positively with glycemic control. To illustrate, compared with the 40-49 age group, the 70-79 age group had an increased likelihood of hospitalization (OR $=1.97,95 \%$ $\mathrm{CI}=1.28,3.04)$, but a decreased likelihood of poor glycemic control $(\mathrm{OR}=0.45,95 \% \mathrm{CI}=0.37,0.56)$. These associations remained significant even with additional adjustments for covariates, though a large reduction was observed in the magnitude of the association between age and hospitalization. Prior hospitalization and prior poor glycemic control were strong predictors for later hospitalization and later poor glycemic control respectively, but not for the other. Hypertension and duration of diabetes were commonly related to both outcomes. For example, a longer duration of diabetes was associated with higher risks relative to a shorter duration of diabetes, shown by ORs for $\geq 9$ yrs vs 35 yrs of $1.83(95 \% \mathrm{CI}=1.36-2.43)$ for hospitalization and of $1.50(95 \% \mathrm{CI}=1.31,1.73)$ for poor glycemiccontrol. Adjusting for covariates only slightly reduced the magnitude of associations. Patterns of association were similar for the number of complications and continuity of care with strong associations only with hospitalizations. Hypercholesterolemia only showed associations with poor glycemic control and a substantial reduction in the magnitude of association was observed after adjustment. There was no evidence that BMI was associated with hospitalization and glycemic control. 
Table 3 Associations* (Odds Ratio, 95\% confidence interval) of age and other predictors (2007-2008) with hospitalization and poor glycemic control (2009)

\begin{tabular}{|c|c|c|c|c|}
\hline & \multirow{3}{*}{$\begin{array}{l}\text { Hospitalization } \\
\text { Model } 1 \\
\text { OR(Cl) }\end{array}$} & \multicolumn{3}{|c|}{ Poor glycemic control } \\
\hline & & Model 2 & Model 1 & Model 2 \\
\hline & & $\mathrm{OR}(\mathrm{Cl})$ & $\mathrm{OR}(\mathrm{Cl})$ & $\mathrm{OR}(\mathrm{Cl})$ \\
\hline \multicolumn{5}{|l|}{ Age groups } \\
\hline $40-49$ & Reference & - & - & - \\
\hline $50-59$ & $1.34(0.98,1.83)$ & $1.09(0.77,1.54)$ & $0.74(0.63,0.88)$ & $0.85(0.70,1.05)$ \\
\hline $60-69$ & $1.70(1.24,2.33)$ & $1.21(0.91,1.60)$ & $0.57(0.48,0.67)$ & $0.65(0.52,0.80)$ \\
\hline $70-79$ & $1.97(1.28,3.04)$ & $1.47(1.03,2.12)$ & $0.45(0.37,0.56)$ & $0.48(0.38,0.60)$ \\
\hline \multicolumn{5}{|l|}{ Prior hospitalization } \\
\hline No & Reference & - & - & - \\
\hline Hospitalized & $2.83(2.07,3.85)$ & $2.04(1.49,2.78)$ & $1.08(0.88,1.32)$ & $1.16(0.93,1.43)$ \\
\hline \multicolumn{5}{|l|}{ Prior glycemic control } \\
\hline Controlled & Reference & - & - & - \\
\hline Uncontrolled ( $\geq 126 \mathrm{mg} / \mathrm{dL}$ ) & $1.27(0.97,1.64)$ & $1.25(0.96,1.63)$ & $3.49(3.08,3.95)$ & $3.33(2.94,3.70)$ \\
\hline \multicolumn{5}{|l|}{ Hypertension $^{\dagger}$} \\
\hline Normal & Reference & - & - & - \\
\hline Hypertensive & $1.32(1.07,1.63)$ & $1.30(1.05,1.60)$ & $1.15(1.00,1.32)$ & $1.15(1.00,1.33)$ \\
\hline \multicolumn{5}{|l|}{ Total cholesterol level } \\
\hline Desirable & Reference & - & - & - \\
\hline High ( $\geq 240$ mg/dL) & $1.28(0.83,1.93)$ & $1.27(0.83,1.94)$ & $1.24(1.03,1.49)$ & $1.21(1.01,1.46)$ \\
\hline \multicolumn{5}{|l|}{$\mathrm{BMl}, \mathrm{kg} / \mathrm{m}^{2}$} \\
\hline Normal $(<25)$ & Reference & - & - & - \\
\hline Overweight(25-29.9) & $1.31(0.80,2.16)$ & $1.39(0.83,2.32)$ & $1.02(0.77,1.34)$ & $1.04(0.79,1.39)$ \\
\hline Obese $(\geq 30)$ & $1.39(0.83,2.31)$ & $1.43(0.86,2.38)$ & $1.03(0.78,1.36)$ & $1.09(0.82,1.45)$ \\
\hline \multicolumn{5}{|l|}{ Duration of diabetes } \\
\hline $3-5 \mathrm{yrs}$ & Reference & - & - & - \\
\hline $6-8 \mathrm{yrs}$ & $1.59(1.16,2.17)$ & $1.45(1.05,2.00)$ & $1.24(1.06,1.44)$ & $1.17(0.99,1.37)$ \\
\hline$\geq 9 \mathrm{yrs}$ & $1.83(1.362 .43)$ & $1.62(1.21,2.18)$ & $1.50(1.31,1.73)$ & $1.39(1.19,1.61)$ \\
\hline \multicolumn{5}{|l|}{ Number of complications } \\
\hline No & Reference & - & - & - \\
\hline $1-2$ & $1.85(1.39,2.44)$ & $1.43(1.04,1.92)$ & $0.94(0.78,1.14)$ & $0.93(0.76,1.14)$ \\
\hline$\geq 3$ & $3.52(2.41,5.12)$ & $2.27(1.49,3.33)$ & $0.93(0.77,1.13)$ & $0.88(0.71,1.10)$ \\
\hline \multicolumn{5}{|l|}{ Continuity of care ${ }^{\ddagger}$} \\
\hline High & Reference & - & - & - \\
\hline Low & $1.86(1.44,2.38)$ & $1.43(1.10,1.89)$ & $1.11(0.97,1.26)$ & $1.06(0.93,1.22)$ \\
\hline
\end{tabular}

"Associations were estimated using logistic regression. Model 1 was adjusted for gender and age. Model 2 was adjusted for types of main medical institution attended and level of health insurance premium as well as the covariates listed in the table.

${ }^{+} \mathrm{SBP} \geq 140 \mathrm{mmHg}$ or $\mathrm{DBP} \geq 90 \mathrm{mmHg}$.

${ }^{\ddagger} \mathrm{High}$, if Continuity of Care Index $=1$ and low otherwise.

When testing an independent association of age for the two outcomes, ORs for age was attenuated slightly with a simultaneous adjustment for each predictor, suggesting that age has an independent association. The largest change in the OR for age was observed following the adjustment for continuity of care in the association with hospitalization (13.8\% reduction in the OR between $70-79$ vs $40-49$ from
1.97 to 1.72 ) (Table 4). Finally, there was little evidence of a moderating effect of other predictors on the associations between age and two outcome variables, except for continuity of care for hospitalization ( $p$ for interaction $<0.001$ ); the association between age and hospitalization was stronger for those with low continuity of care than those with high continuity of care (Figure 1). 
Table 4 Changes in Odds Ratio ${ }^{*}$ (95\% confidence interval) of age for hospitalization and poor glycemic control with introduction of covariates

\begin{tabular}{|c|c|c|c|c|c|c|c|c|c|}
\hline & $\begin{array}{l}\text { Age and } \\
\text { sex alone }\end{array}$ & $\begin{array}{c}\text { Prior } \\
\text { hospitalization }\end{array}$ & $\begin{array}{c}\text { Prior } \\
\text { glycemic } \\
\text { control }\end{array}$ & Hypertension $^{\dagger}$ & $\begin{array}{c}\text { Total } \\
\text { cholesterol } \\
\text { level }\end{array}$ & BMl, $\mathrm{kg} / \mathrm{m}^{2}$ & $\begin{array}{l}\text { Duration } \\
\text { of diabetes }\end{array}$ & $\begin{array}{c}\text { Number of } \\
\text { complications }\end{array}$ & $\begin{array}{l}\text { Continuity } \\
\text { of care }^{\ddagger}\end{array}$ \\
\hline & $\mathrm{OR}(\mathrm{Cl})$ & $\mathrm{OR}(\mathrm{Cl})$ & $\mathrm{OR}(\mathrm{Cl})$ & $\mathrm{OR}(\mathrm{Cl})$ & $\mathrm{OR}(\mathrm{Cl})$ & $\mathrm{OR}(\mathrm{Cl})$ & $\mathrm{OR}(\mathrm{Cl})$ & $\mathrm{OR}(\mathrm{Cl})$ & $\mathrm{OR}(\mathrm{Cl})$ \\
\hline \multicolumn{10}{|c|}{ Hospitalization } \\
\hline \multicolumn{10}{|c|}{ Age groups } \\
\hline $40-49$ & Reference & - & - & - & - & - & - & - & - \\
\hline $50-59$ & $1.34(0.98,1.83)$ & $1.31(0.95,1.80)$ & $1.33(0.97,1.83)$ & $1.32(0.96,1.82)$ & $1.33(0.97,1.83)$ & $1.34(0.98,1.83)$ & $1.30(0.95,1.78)$ & $1.28(0.93,1.75)$ & $1.31(0.96,1.81)$ \\
\hline $60-69$ & $1.70(1.24,2.33)$ & $1.61(1.17,2.21)$ & $1.69(1.23,2.33)$ & $1.63(1.20,2.26)$ & $1.68(1.22,2.31)$ & $1.69(1.24,2.33)$ & $1.59(1.16,2.18)$ & $1.55(1.12,2.13)$ & $1.57(1.14,2.16)$ \\
\hline $70-79$ & $1.97(1.28,3.04)$ & $1.85(1.19,2.86)$ & $2.00(1.30,3.11)$ & $1.95(1.24,2.97)$ & $1.96(1.27,3.04)$ & $1.98(1.28,3.06)$ & $1.76(1.14,2.72)$ & $1.74(1.12,2.69)$ & $1.72(1.11,2.67)$ \\
\hline \multicolumn{10}{|c|}{ Poor glycemic control } \\
\hline \multicolumn{10}{|c|}{ Age groups } \\
\hline $40-49$ & Reference & - & - & - & - & - & - & - & - \\
\hline $50-59$ & $0.74(0.63,0.88)$ & $0.74(0.63,0.88)$ & $0.76(0.64,0.91)$ & $0.75(0.64,0.90)$ & $0.73(0.62,0.86)$ & $0.74(0.63,0.88)$ & $0.72(0.60,0.85)$ & $0.74(0.63,0.88)$ & $0.73(0.62,0.87)$ \\
\hline $60-69$ & $0.57(0.48,0.67)$ & $0.57(0.48,0.67)$ & $0.59(0.50,0.70)$ & $0.59(0.50,0.69)$ & $0.54(0.46,0.65)$ & $0.57(0.48,0.67)$ & $0.53(0.45,0.63)$ & $0.57(0.48,0.67)$ & $0.55(0.47,0.65)$ \\
\hline $70-79$ & $0.45(0.37,0.56)$ & $0.45(0.37,0.56)$ & $0.52(0.42,0.65)$ & $0.47(0.39,0.59)$ & $0.43(0.35,0.54)$ & $0.45(0.37,0.55)$ & $0.40(0.33,0.50)$ & $0.45(0.36,0.55)$ & $0.43(0.35,0.53)$ \\
\hline
\end{tabular}

Odds ratios were estimated using logistic regression. Each covariate was added to a model with age and sex

$\mathrm{SBP} \geq 140 \mathrm{mmHg}$ or DBP $\geq 90 \mathrm{mmHg}$.

High, if Continuity of Care Index $=1$ and low otherwise. 


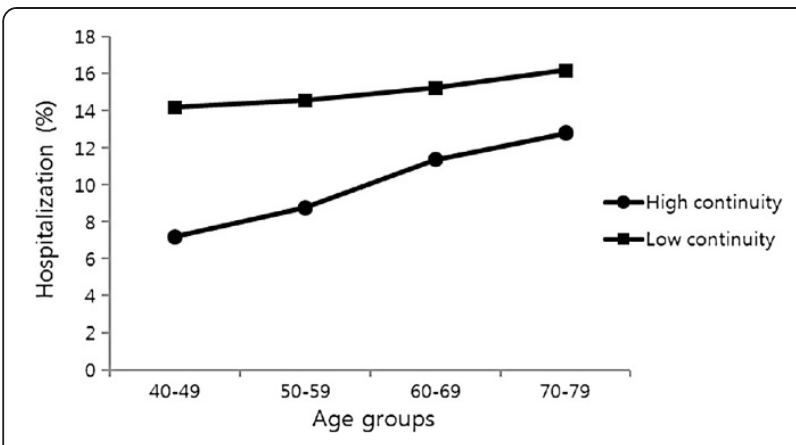

Figure 1 Adjusted prevalence ${ }^{\dagger}$ of hospitalization(2009) by age groups and continuity of care (2007-2008). ${ }^{\dagger}$ All prevalence estimates were obtained from multivariate models adjusted for gender.

\section{Discussion}

About half (51.9\%) of the patients with diabetes achieved the conventional goal of glycemic control (FPG $<126 \mathrm{mg} /$ $\mathrm{dL}$ ) and better glycemic control was observed among the older groups. Age was associated with both hospitalization and poor glycemic control, but in opposite directions. The trend remained after adjustment for covariates, suggesting that age is a major independent predictor both for a greater risk of hospitalization and for better glycemic control. No interactions were observed for any combination of age and other covariates, except for age and continuity of care for hospitalization. Factors were differently associated with increased hospitalization and poor glycemic control. For example, metabolic control, such as the levels of FPG and total cholesterol, was an important predictor for poor glycemic control, while prior hospitalization, number of complications, and continuity of care only predicted a higher risk of hospitalization. Hypertension and a longer duration of diabetes were unfavourably related to both outcomes, but no effect was observed for BMI.

\section{Methodological consideration}

This study has several strengths; i) it is nationally representative with diabetic patients from various types of hospitals and clinics, while other studies have focused solely one level of health delivery (i.e., only hospital patients $[5,31,32]$ or only primary care patients [7]), or narrowly targeted patient recruitment from a few clinics $[31,32]$; ii) it included a range of clinical variables including laboratory data, which have rarely been investigated concurrently, primarily because of the limited availability of such data; and iii) substantial adjustments were made for possible confounding factors such as BMI and continuity of care, which seem to involve age-related differences in diabetes outcomes.

We also note some limitations. Though HbA1c has been acknowledged as a primary test for monitoring of glycemic control, a single measure of FPG was used for an assessment of glycemic control, as HbA1c was not a routine measure in health examinations by Korean National Health Insurance. Even with this limitation, FPG could provide a certain value on the grounds that day-to-day management of diabetic patients including self-monitoring is frequently based on glucose level and some studies support a direct correlation between FPG and HbA1c [33]. Second, whilst the diagnosis of diabetes using insurance claims data can be prone to some inaccuracy, this may not be a major issue in the current study, as we included patients only when they provided health records of diabetes care for at least four (for participants who included in 2006) and to nine (for those who included in 2001) consecutive years. The reliability of diabetes diagnosis was assured by results from a validity study with Korean National Health Insurance Data, which found diagnostic accuracy of $87.2 \%$ for in-patients and 72.3\% for out-patients [34]. Thirdly, though the glucose levels of those who were on diabetes medication may have been influenced by types of treatment [11], we did not deal with treatment modality because of the lack of relevant information. As such, we could not examine the possibility, if strict glycemic control among older patients is primarily attributable to treatment choice.

\section{Interpretation and comparison with previous studies}

Tighter glycemic control increased incrementally with age. This was contrary to the association between age and hospitalization which showed a consistent increase with advancing ages, correspondingly to the progressive nature of the disease. There are several possible explanations for these findings; true age effects, confounding effects due to characteristics other than age, or a combination of these. In a prior study with a community sample [16], age was not a main predictor in a multivariate analysis, though the best glycemic control was observed among the oldest group. In contrast, other studies [9-11,20] have shown that the age effect remained even after adjustments for duration of diabetes, treatment modality, BMI and emotional distress, supporting the true age effects, which was similarly noted in the current study.

One interpretation is that the older diabetic patients are more susceptible to glycemic control, partly as a result of the increased need for higher dosage and intensified medications to control blood glucose [35]. Consequently, blood glucose values amongst older patients are likely to fluctuate over time and at the same time to have a higher risk of hypoglycemia, and thereby result in a lower average of blood glucose level [36]. This indicates that tight glucose control may have little benefit among older diabetic patients. Second, as evidence [37] suggests, early-onset diabetes may represent different phenotype, with greater beta-cell dysfunction, than late-onset. This may offer a 
potential explanation as to why younger age is associated with poor glycemic control, though we could not confirm whether the onset of diabetes in middle-aged patients is earlier than that of older patients.

We examined the role of covariates for confounding and mediating effect in the associations between age and hospitalization and glycemic control. A simultaneous adjustment between age and each covariate generally resulted in small changes in the age effect. With a large change in the magnitude, continuity of care partially accounts for the association between age and hospitalization. Additionally, a significant interaction was observed between continuity of care and age for hospitalization; there was a more noticeable benefit of continuity of care for hospitalization among the young patients with diabetes, but less benefit among the older patients. Most likely, worsened glycemic control leads to a higher continuity of care among the older patients rather than vice versa. Though the explanation is tentative and requires further confirmation, this carries particular policy implications in Korea, where referrals between specialist and primary care are loosely organized with the shortage of general practitioners. In Korea, the decision of which type of clinic to go for treatment largely depends on the patient's own choice and they are easily directed towards a discontinuation of coordinated care. Thus, this finding suggests that improving continuity of care may be an effective intervention to respond to gaps in diabetes care in Korea.

We found that risk factors were different for hospitalization and glycemic control. Metabolic control such as glucose and total cholesterol level predicted glycemic control well but did poorly on hospitalization, while prior hospitalization, number of complications, and continuity of care were associated with hospitalization but not with glycemic control. Particularly, associations with hospitalization were modestly affected by glycemic control (i.e., achieving $\mathrm{FPG}<126 \mathrm{mg} / \mathrm{dL}$ ), not reaching statistical significance ( $\mathrm{p}=0.08$ in multivariate analysis). One possible interpretation would be that, as seen in some previous studies $[38,39]$, the association with glucose level may be less obvious with non-cardiovascular diseases than that in cardiovascular diseases. To confirm if this is the case, sub-categories of hospitalization in this study may need to be differentiated, which would be worthwhile for a future study. Alternatively, the older diabetic patients have a higher risk of hospitalization due to hypoglycaemia [35], which generates a U-shaped association between glucose level and hospitalization [40], although some studies [7,31] supported linear or threshold effects. In general, different sets of risk factors partially explain the disparity between a higher hospitalization and a better glycemic control amongst older diabetic patients and suggest a more comprehensive approach to reduce hospitalization. This implies that the current threshold of FPG used to indicate a conventional treatment goal might not be sufficient by itself to identify the risk of hospitalization among older patients with diabetes. Therefore, our findings provide support for the recent guidelines [41], which outlined an individualized approach with the recognition of wide functional heterogeneity and clinical complexity common in older patients with diabetes.

\section{Conclusion}

A higher hospitalization among the older diabetic patients appeared in the presence of better glycemic control. The disparity between increased hospitalization and improved glycemic control highlighted a difficulty in treatment decisions for older diabetic patients. Factors were differently associated with these two outcomes, providing more comprehensive risk profiles for hospitalization. An emphasis on a geriatric evaluation to include functional and comorbidity status should be addressed for the care of older diabetic patients.

\section{Consent}

This study used secondary data without personal identifier, for which no informed consent is necessary.

\section{Competing interests \\ The authors declare that they have no conflicts of interest concerning this} article.

\section{Authors' contributions}

MK and BN conceived and designed the study. MK and SB performed the analyses. YY SB. MK, BN, NK, YY and MH wrote original and subsequent drafts. All authors read and approved the final manuscript.

\section{Acknowledgements}

This research was financially supported by a grant of the Korean Health Insurance Service, awarded to MK and BN. The funders had no role in study design, data analysis, decision to publish, or preparation of the manuscript.

\section{Author details}

'Department of Preventive Medicine, School of Medicine, Eulji University, Daejeon, Korea. ${ }^{2}$ Institute for Health Insurance Policy Research, National Health Insurance Service, Seoul, Korea. ${ }^{3}$ Department of Internal Medicine, College of Medicine, Korea University, Seoul, Korea. ${ }^{4}$ Stress Research Institute, Stockholm University, Stockholm, Sweden. ${ }^{5}$ Department of Preventive Medicine, College of Medicine, Konyang University, Konyang Univ. Gwanjeo Campus, Gasuwon-dong, Seo-gu, Daejeon 302-833, Korea.

Received: 30 April 2014 Accepted: 29 September 2014 Published: 16 October 2014

\section{References}

1. Danaei G, Finucane MM, Lu Y, Singh GM, Cowan MJ, Paciorek CJ, Lin JK, Farzadfar F, Khang YH, Stevens GA, Rao M, Ali MK, Riley LM, Robinson CA, Ezzati M: National, regional, and global trends in fasting plasma glucose and diabetes prevalence since 1980: systematic analysis of health examination surveys and epidemiological studies with 370 country-years and 2.7 million participants. Lancet 2011, 378(9785):31-40.

2. Wild S, Roglic G, Green A, Sicree R, King H: Global prevalence of diabetes: estimates for the year 2000 and projections for 2030. Diabetes Care 2004, 27(5):1047-1053.

3. Korea Centers for Disease Control and Prevention: National Health Statistics: Korea National Health and Nutrition Examination Survey (V-1, 2010). 2011. 
4. Corriere M, Rooparinesingh N, Kalyani RR: Epidemiology of diabetes and diabetes complications in the elderly: an emerging public health burden. Curr Diab Rep 2013, 13(6):805-813.

5. Kim H, Helmer DA, Zhao Z, Boockvar K: Potentially preventable hospitalizations among older adults with diabetes. Am J Manag Care 2011, 17(11):e419-426.

6. $\mathrm{Ng} \mathrm{E}, \mathrm{McGrail} \mathrm{KM}$, Johnson JA: Hospitalization risk in a type 2 diabetes cohort. Health Rep 2010, 21(3):29-35.

7. Tomlin AM, Dovey SM, Tilyard MW: Risk factors for hospitalization due to diabetes complications. Diabetes Res Clin Pract 2008, 80(2):244-252.

8. Barnett KN, McMurdo ME, Ogston SA, Morris AD, Evans JM: Mortality in people diagnosed with type 2 diabetes at an older age: a systematic review. Age Ageing 2006, 35(5):463-468.

9. Chew BH, Shariff Ghazali S, Ismail M, Haniff J, Bujang MA: Age $>/=60$ years was an independent risk factor for diabetes-related complications despite good control of cardiovascular risk factors in patients with type 2 diabetes mellitus. Exp Gerontol 2013, 48(5):485-491.

10. Sundquist K, Chaikiat A, Leon VR, Johansson SE, Sundquist J: Country of birth, socioeconomic factors, and risk factor control in patients with type 2 diabetes: a Swedish study from 25 primary health-care centres. Diabetes Metab Res Rev 2011, 27(3):244-254.

11. Chiu CJ, Wray LA: Factors predicting glycemic control in middle-aged and older adults with type 2 diabetes. Prev Chronic Dis 2010, 7(1):A08

12. Fox KM, Gerber Pharmd RA, Bolinder B, Chen J, Kumar S: Prevalence of inadequate glycemic control among patients with type 2 diabetes in the United Kingdom general practice research database: A series of retrospective analyses of data from 1998 through 2002. Clin Ther 2006, 28(3):388-395.

13. Benoit SR, Fleming R, Philis-Tsimikas A, Ji M: Predictors of glycemic control among patients with Type 2 diabetes: a longitudinal study. BMC Public Health 2005, 5:36.

14. Song $\mathrm{CH}$, Won YJ, Ryu JS, Shin YG, Chung CH, Choi DH, Song YD: Clinical characteristics of elderly diabetics diagnosed after 60 years Old. Kor J Med 1996, 51(2):234-242.

15. Suh DC, Kim CM, Choi IS, Plauschinat CA: Comorbid conditions and glycemic control in elderly patients with type 2 diabetes mellitus, 1988 to 1994 to 1999 to 2004. J Am Geriatr Soc 2008, 56(3):484-492.

16. Shorr RI, Franse LV, Resnick HE, Di Bari M, Johnson KC, Pahor M: Glycemic control of older adults with type 2 diabetes: findings from the third national health and nutrition examination survey, 1988-1994. J Am Geriatr Soc 2000, 48(3):264-267.

17. Pornet C, Bourdel-Marchasson I, Lecomte P, Eschwege E, Romon I, Fosse S, Assogba F, Roudier C, Fagot-Campagna A, Committee ES: Trends in the quality of care for elderly people with type 2 diabetes: the need for improvements in safety and quality (the 2001 and 2007 ENTRED Surveys). Diabetes Metab 2011, 37(2):152-161.

18. Janssen I: Influence of age on the relation between waist circumference and cardiometabolic risk markers. Nutr Metab Cardiovasc Dis 2009, 19(3):163-169.

19. Bruce DG, Davis WA, Davis TM: Glycemic control in older subjects with type 2 diabetes mellitus in the Fremantle diabetes study. J Am Geriatr Soc 2000, 48(11):1449-1453.

20. Nichols GA, Hillier TA, Javor K, Brown JB: Predictors of glycemic control in insulin-using adults with type 2 diabetes. Diabetes Care 2000, 23(3):273-277

21. Juarez DT, Sentell T, Tokumaru S, Goo R, Davis JW, Mau MM: Factors associated with poor glycemic control or wide glycemic variability among diabetes patients in Hawaii, 2006-2009. Prev Chronic Dis 2012, 9:120065.

22. Agency for Healthcare Research and Quality: All Prevention Quality Indicators Technical Specifications, Version 4.5. Accessible: http://www.qualityindicators. ahrq.gov/Modules/PQI_TechSpec.aspx [Access date February 23 2014]

23. Clarke $P$, Kelman C, Colagiuri S: Factors influencing the cost of hospital care for people with diabetes in Australia. J Diab Complications 2006, 20(6):349-355.

24. Organisation for Economic Co-operation and Development: Health at a Glance 2013: OECD Indicators. Accessible: http://www.oecd.org/els/healthsystems/Health-at-a-Glance-2013.pdf [Access date February 22 2014]

25. Hong JS, Kang HC: Continuity of ambulatory care and health outcomes in adult patients with type 2 diabetes in Korea. Health Policy 2013, 109(2):158-165
26. van Walraven C, Oake N, Jennings A, Forster AJ: The association between continuity of care and outcomes: a systematic and critical review. J Eval Clin Pract 2010, 16(5):947-956.

27. National Health Insurance Corporation: Data construction of National Health Insurance Cohort. 2010

28. American Diabetes Association: Standards of medical care in diabetes2014. Diabetes Care 2014, 37(Suppl 1):S14-80.

29. Expert Panel on Detection, Evaluation and Treatment of High Blood Cholesterol in Adult: Executive summary of the third report of the national cholesterol education program (NCEP) expert panel on detection, evaluation, and treatment of high blood cholesterol in adults (adult treatment panel III). JAMA 2001, 285(19):2486-2497.

30. Sinclair A, Morley JE, Rodriguez-Manas L, Paolisso G, Bayer T, Zeyfang A, Bourdel-Marchasson I, Vischer U, Woo J, Chapman I, Dunning T, Meneilly G, Rodriguez-Saldana J, Gutierrez Robledo LM, Cukierman-Yaffe T, Gadsby R, Schernthaner G, Lorig K: Diabetes mellitus in older people: position statement on behalf of the international association of gerontology and geriatrics (IAGG), the European diabetes working party for older people (EDWPOP), and the international task force of experts in diabetes. J Am Med Dir Assoc 2012, 13(6):497-502.

31. Bo S, Ciccone G, Grassi G, Gancia R, Rosato R, Merletti F, Pagano GF: Patients with type 2 diabetes had higher rates of hospitalization than the general population. J Clin Epidemiol 2004, 57(11):1196-1201.

32. Rosenthal MJ, Fajardo M, Gilmore S, Morley JE, Naliboff BD: Hospitalization and mortality of diabetes in older adults. A 3-year prospective study. Diab Care 1998, 21(2):231-235.

33. Rohlfing CL, Wiedmeyer HM, Little RR, England JD, Tennill A, Goldstein DE: Defining the relationship between plasma glucose and $\mathrm{HbA}(1 \mathrm{c})$ : analysis of glucose profiles and $\mathrm{HbA}(1 \mathrm{c})$ in the diabetes control and complications trial. Diab Care 2002, 25(2):275-278.

34. Task Force Team for Basic Statistical Study of Korean Diabetes Mellitus: Diabetes in Korea 2007. In Korean Diabetes Association \& Health Insurance Review and Assessment Service. 2007.

35. Szerszen A, Seminara DP, Castellanos MR: Glucose control in the hospitalized elderly-a concern not just for patients with diabetes. Geriatrics 2009, 64(6):18-20.

36. Meneilly GS, Veldhuis JD, Elahi D: Pulsatile insulin secretion in elderly patients with diabetes. Diab Res Clin Pract 2006, 73(2):218-220.

37. Wannamethee SG, Shaper AG, Whincup PH, Lennon L, Sattar N: Impact of diabetes on cardiovascular disease risk and all-cause mortality in older men: influence of age at onset, diabetes duration, and established and novel risk factors. Arch Intern Med 2011, 171(5):404-410.

38. Eeg-Olofsson K, Cederholm J, Nilsson PM, Zethelius B, Svensson AM, Gudbjornsdottir S, Eliasson B: New aspects of $\mathrm{HbA1C}$ as a risk factor for cardiovascular diseases in type 2 diabetes: an observational study from the Swedish National Diabetes Register (NDR). J Intern Med 2010, 268(5):471-482.

39. Kim YK, Lee JE, Kim YG, Kim DJ, Oh HY, Yang CW, Kim KW, Huh W: Cardiac autonomic neuropathy as a predictor of deterioration of the renal function in normoalbuminuric, normotensive patients with type 2 diabetes mellitus. J Korean Med Sci 2009, 24(Suppl):S69-74

40. Nichols GA, Joshua-Gotlib S, Parasuraman S: Glycemic control and risk of cardiovascular disease hospitalization and all-cause mortality. J Am Coll Cardiol 2013, 62(2):121-127

41. American Geriatrics Society Expert Panel on Care of Older Adults with Diabetes Mellitus, Moreno G, Mangione CM, Kimbro L, Vaisberg E: Guidelines abstracted from the American geriatrics society guidelines for improving the care of older adults with diabetes mellitus: 2013 update. J Am Geriatr Soc 2013, 61(11):2020-2026.

doi:10.1186/1471-2318-14-111

Cite this article as: Ki et al:: Age-related differences in diabetes care outcomes in Korea: a retrospective cohort study. BMC Geriatrics 2014 14:111. 